\title{
Vitrectomy Versus Combined Vitrectomy-Scleral Buckling for the Treatment of Pseudophakic and Aphakic Retinal Detachment
}

\author{
Dr Gareebbagdadi MD ${ }^{1 *}$, Dr Khalifa Alsawid MSc ${ }^{2}$ and Dr khalid AK elmajri MSc ${ }^{3}$ \\ ${ }^{1}$ Triploi eye hospital, Libya \\ ${ }^{2}$ FRCSTriploi eye hospital, Libya \\ ${ }^{3}$ Alwahda teaching hospital, Libya
}

*Corresponding author: Dr Gareebbagdadi MD, Triploi eye hospital, Libya.

Received Date: May 09, 2021

Published Date: May 22, 2021

\begin{abstract}
There is a disagreement on the ideal intervention for pseudophakic and aphakic retinal detachment. The goal of this thesis is to outline the difference between the two surgical approaches in getting higher reattachment rates and better visual outcomes. The study is a prospective randomised study to evaluate the efficacy of vitrectomy alone versus a combination of both vitrectomy and scleral buckling in the treatment of pseudophakic and aphakic retinal detachment.

Aim of the work: The aim of this study is to compare the anatomical and functional results of primary vitrectomy alone versus vitrectomyscleral buckling for pseudophakic and aphakic retinal detachment.

Patients and methods: A total of 30 eyes with pseudophakic or aphakic retinal detachment will be divided into two groups. Fifteen consecutive pseudophakic or aphakic eyes with retinal detachment will be operated by vitrectomy-scleral buckling (Group-A) and Fifteen additional patients will be operated by vitrectomy alone (Group-B).

Results: The two groups of the patients with a postoperative follow-up of at least 6 months continue to maintain an attached retina after one operation. Visual acuity has improved by at least 2 lines on the Snellen chart in 25 patients, remained the same in 2 patients, and decreased in 1 patient.

Conclusion: This randomised study shows the same anatomic results when performing a PPV, fluid-air exchange, internal drainage, and endolaser together and SF6 gas injection with or without an scleral buckling for pseudophakic retinal detachment.
\end{abstract}

\section{Introduction}

Pseudophakic or aphakic retinal detachment is one of the most devastating complications faced after cataract surgery and may result in permanent reduction of visual acuity. However, some patients may restore good vision, if treated adequately and promptly. Pseudophakic or aphakic retinal detachment is a result of retinaltear or tears that develop following cataract surgery. The detachment might be predisposed by myopia, vitreous loss or YAG capsulotomy that leads to early liquefaction of the vitreous with subsequent development of posterior vitreous detachment. Repair of pseudophakic or a phakic retinal detachment is an ongoing challenge for the vitreoretinal surgeon. A variety of options have been advocated for the surgical treatment of pseudophakic retinal detachment including pneumatic retinopexy, scleral buckling, pars plana vitrectomy and a combination of both scleral buckling-pars plana vitrectomy. 


\section{Pars plana vitrectomy}

Some authors advocate operating on patients with pseudophakic or aphakic retinal detachment by using pars plana vitrectomy. PPV provides meticulous fundus examination in comparison to the in-direct ophthalmoscopy in viewing pseudophakic retinal detachment because the fundus view is often impaired by anterior or posterior capsular opacification, reflections related to the intraocular lens, or poor mydriasis. PPV will allow efficient examination of the peripheral retina and detection of minute holes, which if left untreated may cause recurrent retinal detachment. Senn P, et al. [1], Speicher MA, et al. [2] reported that primary pars plana vitrectomy is a highly effective treatment modality for the repair of pseudophakic retinal detachment. In [3] Campo RV, et al. stated that primary pars plana vitrectomy is an effective and safe method to repair pseudophakic retinal detachments. They all concluded that the anatomical and the visual acuity obtained with this technique appear to be at least as good as for scleral buckling alone, a combination of both pars plana vitrectomy-scleral buckling, and pneumatic retinopexy. Primary vitrectomy for pseudophakic and aphakic retinal detachments improves the reattachment rate by allowing a direct controlled attack on the cause of the detachment and release of vitreoretinal traction by an internal approach and at the same time avoiding many intraoperative and postoperative complications of scleral buckling such as postoperative anterior segment ischemia, central retinal artery occlusion and sever motility disturbance [4]. Additionally reported that choroidal haemorrhage, retinal perforation which might lead to creation of tears or breaks, endothalmitis and subretinal neovascularization may complicate a scleral buckling procedure with drainage of subretinal fluid. Moreover Cheng-lien Ho, et al. [5] showed that encircling buckling produces changes of refractive status due to the interference in the axial length of the eye. However pars plana vitrectomy is not devoid of possible complications, it may be complicated bycataract, postoperative vitreous haemorrhage, persistent corneal epithelial defects as well as endophthalmiltis. In additioniatrogenic retinal breaks, which if undetected may lead to rhegmatogenous retinal detachment [6]. Postoperative vitreous haemorrhage. Other complications are sub-retinal or supra-choroidal infusion of fluid, air, silicone or perfluorocarbon liquid. In addition foveal injury during endolaser treatment as well as high intraocular pressure during silicone oil infusion [7]. Furthermore, Machmer R, et al. [8] reported that retinal or choroidal bleeding and corneal oedema may be frequently encountered during vitrectomy.

\section{Combined of vitrectomy and scleral buckling}

Scleral buckling is an adjunctive procedure to pars plana vitrectomy because it gives further support and acts as an external tamponade to the retinal beak or breaks. Devenyi RG, et al. [9] concluded that a combined scleral buckle and pars plana vitrectomy approach to primary pseudophakic retinal detachment offers significant benefits to scleral buckling alone in improving peripheral visibility, resulting in fewer missed peripheral breaks as well as a lower probability of proliferative vitreoretinopathy. In addition, Berrod JP, et al. [10] and Wael El-Haig, et al. [11] reported that combination of both vitrectomy-scleral buckling gives a higher reattachment rates and better visual outcomes in comparison to conventional scleral buckling for the treatment of pseudophakic retinal detachment. Moreover, Escoffery RF, et al. [12-17] reported that scleral buckling should be placed in eyes with a preoperative PVR of grade $\mathrm{C}$ or more to prevent recurrent RRD from recurrent postoperative PVR formation.

\section{Methods}

\section{Methods}

All patients well be examined pre- and postoperatively.

Preoperative evaluation: A medical and ophthalmic history will be taken and a complete ophthalmological examination will be carried out including:

- Visual acuity (Snellen chart),

- Intraocular pressure measurement with applanation tonometry.

- $\quad$ Anterior segment examination using slit lamp to assess the clarity of the cornea and the condition of the IOL and the posterior capsule.

- Meticulous and precise preoperative examinations of the posterior segment with indirect ophthalmoscopy and scleral indentation to find all retinal breaks and associated retinal pathology after papillary dilatation with topical tropicamide $1 \%$ and phenylephrine $2.5 \%$ with detailed drawing of the fundus.

- $\quad$ Patients with undetected break will be examined with triple mirror lens.

Operative Techniques: Under local anaesthesia, an eyelid speculum well be inserted after skin preparation and draping of patients.

\section{Pars Plana Vitrectomy}

- A 360-degree or a subtotal conjunctivalperitomy will be performed at the limbus.

- A three-port sclerotomies at a position marked $3 \mathrm{~mm}$ posterior to the limbus.

- A wide field viewing noncontact lens system will be used.

- $\quad$ Accurate identification of the location, number and size of retinal breaks.

- $\quad$ Pars plana vitrectomy using vitreous cutter (complete vitrectomy with removal of posterior hyloid.

- Intraocular diathermy for marking pre-existing retinal tears. 
- Perfluorocarbon liquid is used to flatten the retina.

- After the retina is flattened, all the retinal breaks well be treated with endophotocoagulation. Then 360-degree endolaser photocoagulation will be applied.

- Air-perfluorocarbon exchange will be performed followed by injection of $20 \%$ sulphur hexafluoride.

- $\quad$ Patients well be asked to position themselves face down for 7 days.

- Closing up the sclerotomies with $6 / 0$ vicryl suture as well as the conjunctiva using $7 / 0$ vicryl sutures.

- $\quad$ Eye patch.

A combined of both pars plana vitrectomy and scleral buckling under general anaesthesia

- Performing of a 360-degree limbal conjunctival peritomy.

- Isolation of the four recti muscles with $2 / 0$ silk sutures.

- $\quad$ Placement of 360-degree encircling band no.240. Then fixation of the band by $5 / 0$ mattress sutures in the four quadrants.

- Comprehensive fundus examination with the indirect ophthalmoscopy and localization of the breaks.

- Pars plana vitrectomy as mentioned before.

\section{Inclusion criteria}

- $\quad$ Patients diagnosed with pseudophakic oraphakic retinal detachment.

- $\quad$ No proliferative vitreoretinopathy or PVR stage A +/grade $\mathrm{B}$.

- $\quad$ No previous retinal surgery

3.1.6. Exclusion criteria

- $\quad$ People with mental illness or physical disability who cannot keep postoperative positioning.

- $\quad$ Recurrent Retinal detachment.

- Giant retinal tear

- $\quad$ PVR more than grade B

- Macular hole

Postoperative evaluation: All cases will be examined on the first day postoperatively, first week, one month, three months and then six months. In each visit the patient will have a full ophthalmological examination including:

- Visual acuity (Snellen chart).

- Intraocular pressure measurement with applanation tonometry.
- $\quad$ Anterior segment examination using slit lamp to assess the clarity of the cornea and the condition of the IOL and the posterior capsule.

- $\quad$ Percent of gas fill.

- Meticulous and precise postoperative follow up examination of the posterior segment with indirect ophthalmoscopy to assess the status of the retina and if there is a redevelopment of PVR and its grade if any.

\section{Results}

A total of 30 primary pseuodophakic patients were operated upon during the study period. Peripheral retinal holes were eventually found in all patients; however, 4 eyes $(13 \%)$ required vitrectomy removing capsular or cortical remnants to find the retinal holes. The mean operation time was 82.7 minutes (range 66-93 minutes). After 3 to 14 months of follow-up, all retinas were completely reattached with no PVR of macular pucker. No complications attributable to the vitrectomy procedure occurred. All patients got an increase in their visual acuity at the last followup, when compared to their preoperative visual acuity. An initial scleral buckle alone in our hospital had a 75\% single-operation success rate, and a subsequent need for reoperation, while a combined approach had a $100 \%$ single operation success rate.

\section{Discussion}

Pseuodophakic retinal detachments with missed or incompletely treated tears, and PVR, are most frequently cited reasons for failure. In our series, we could not find a peripheral tear during initial peripheral examination and scleral depression in $4(13.3 \%)$ of cases, but then we were able to find a tear in each patient during vitrectomy. Published single-operation success rates for pseudophakic and aphakic retinal detachments have varied from $61 \%$ to $77 \%$. The rationale for the addition of a pars plana vitrectomy (PPV) with perfluorocarbon liquid to the traditional scleral buckle was that the vitrectomy would allow optimization of the peripheral view. This would occur by clearing capsular opacities and cortical remnants, as well as vitreous opacities or hemorrhage, and also removing all intravitreal and subretinal pigment epithelial cells, thus reducing or preventing the occurrence of PVR. Of course, it would be possible to perform the vitrectomy without perfluorocarbons. In such cases posterior breaks would allow internal drainage by creating posterior retinotomy, but patients would lose the advantages perfluorocarbons offer with respect to peripheral visualization. This procedure would also introduce the potential complications of posterior retinotomy. The present study confirmed that a combined scleral buckling and pars planavitrectomy offered the same improvement in the surgical repair rate of pseudophakic retinal detachments. The improved success rate is a function of vitrectomy contributing to both an improved peripheral visibility and a lower ocurrence of proliferative vitreoretinopathy. 
Table 1: Demographic and preoperative exam finding for PPV versus SB with PPV.

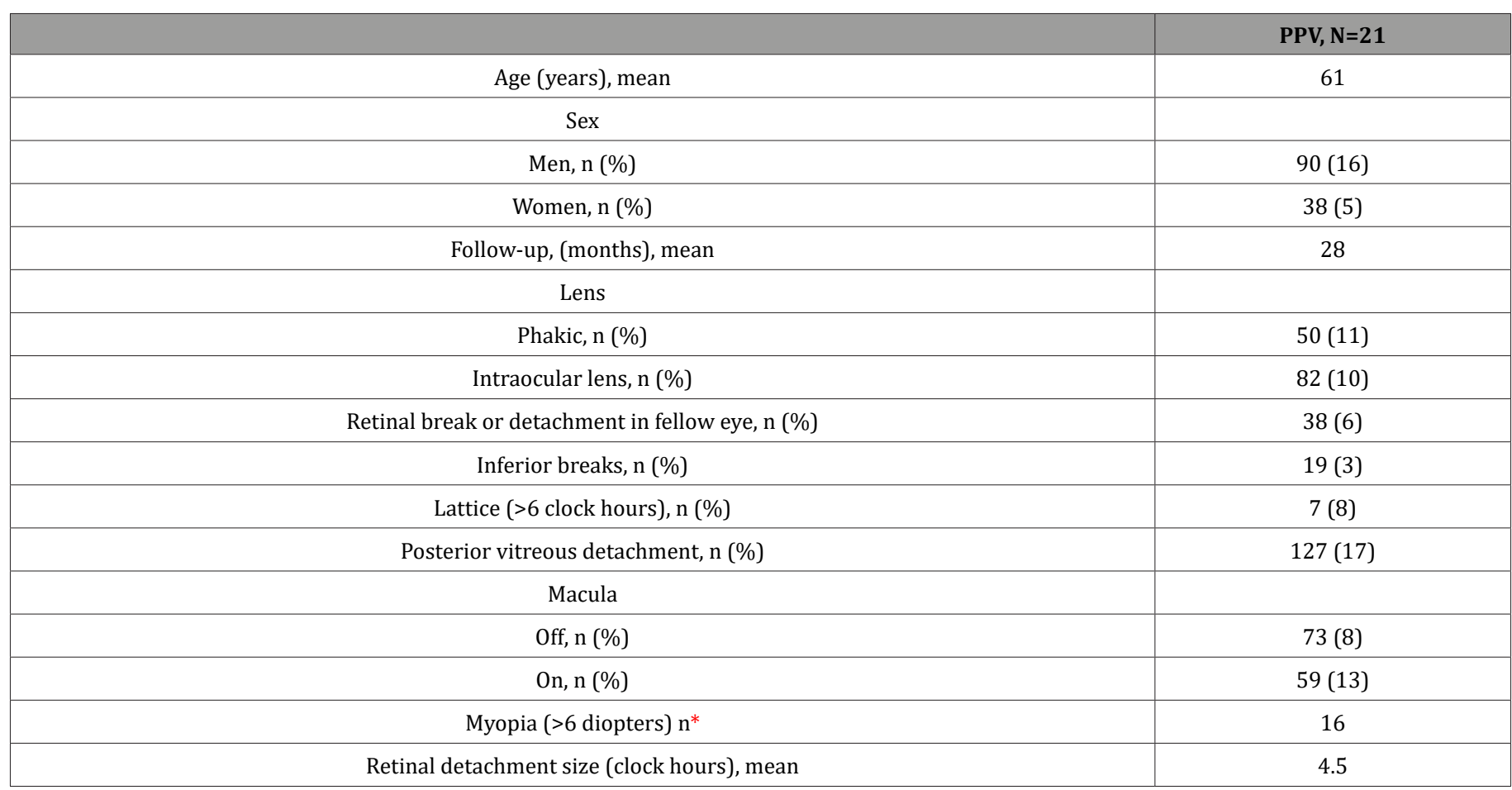

PPV: pars plana vitrectomy; PVR; proliferative vitreoretinopathy; SB: scleral buckling

Table 2: PPV versus with PPV - VA and IOP.

\begin{tabular}{|c|c|c|}
\hline & & VA (LOGMAR) \\
\hline & PPV & 1.19 \\
\hline Preoperative & 1.03 & 2.39 \\
\hline Day 1 & 2.15 & 1.91 \\
\hline Week 1 & 1.27 & 0.99 \\
\hline Month 1 & 0.57 & 0.7 \\
\hline Month 3 & 0.45 & 0.55 \\
\hline Month 6 & 0.39 & 0.37 \\
\hline Final & 0.33 & $20 / 200$ \\
\hline
\end{tabular}

IOP: Intracular pressure; log MAR: Logarithm of the minimum angle of resolution; PPV: Pars Plana Vitrectomy; SB: Scleral buckling; VA: visual acuity

\section{Acknowledgement}

None.

\section{Conflict of Interest}

None.

\section{References}

1. Senn P, Schmid MK, Job O, Hurlimann A, Schipper I (2002) Pars plana vitrectomy for pseudophakic retinal detachment KlinMonatsblAugenheilkd 219(4):226-30.

2. Speicher MA, Fu AD, Martin JP, von Fricken MA (2000) Primary vitrectomy alone for repair of retinal detachments following cataract surgery. Retina 20(5): 459-466.

3. Campo RV, Sipperley JO, Sneed SR, Park DW, Dugel PU, et al. (1999) Pars plana vitrectomy without scleral buckle for pseudophakic retinal detachments. Ophthalmology 106(9): 1811-1815.

4. Shami MJ, Abdul-Rahim AS (2001) Intrusion of a scleral buckle: a late complication of retinal reattachment surgery. Retina 21(2): 195-197.
5. Chang CW, et al. (2002) Ophthalmic Surg Lasers 33(4): 314-318.

6. Silicone Study Group A (1992) Vitrectomy with silicone oil or perflouropropane gas in eyes with sever proliferative vitreoretinopathy: results of a randomised clinical trial-Silicone Study Report 2. Arch Ophthalmol 110(6): 780-792.

7. Silicone Study Group B (1992) Vitrectomy with silicone oil or sulfurhexafluorid gas in eyes with sever proliferative vitreoretinopathy: results of a randomised clinical trial-Silicone Study Report 1. Arch Ophthalmol 110(6): 770-779.

8. Machmer R, McCuen BW, DeJuan E Jr (1986) Relaxing retinotomies and retinectomies. Am J Ophthalmol 102(1): 7-12.

9. Devenyi RG, de Carvalho Nakamura H (1999) Combined scleral buckle and pars plana vitrectomy as a primary procedure for pseudophakic retinal detachments. Ophthalmic Surg Lasers 30(8): 615-618.

10. Berrod JP, Sautiere B, Rozot P, Raspiller A (1997) retinal detachment after cataract surgery. IntOphthalmol 20: 301-308.

11. Wael Osman El-Haig MD, et al. (2001) bull Egyptian OphthalomSoc 94: 4.

12. Escoffery RF, Olk RJ, Grand MG, Boniiuk I (1985) Vitrectomy without scleral bukling for primary RRD. Am J Ophthalmology 99: 275-281. 
13. Pournaras CJ, Kapetanios AD (2003) European Journal of Ophthalmology. (13): 298-306.

14. Le Rouic JF, Behar-Cohen F, Azan F, Bertin S, Bettembourg O, et al. (2002) Vitrectomy without scleral buckle versus ab-externo approach for pseudophakic retinal detachment: comparative retrospective study. J FrOphtalmol 25(3): 240-245.

15. Nguyen QD, Lashkari K, Hirose T, Pruett RC, Mcmeel JW, et al. (2001) Erosion and intrusion of silicone rubber scleral buckle Presentation and management. Retina 21(3): 214-220.
16. Weichel ED, Martidis A, Pineman MS, McNamara JA, Park CH, et al. (2006) Pars plana vitrectomy versus combined pas plana vitrectomy scleral buckle for primary repair of pseudophakic retinal detachment. 113(11): 2033-2040.

17. Brazitikos PD, Androudi S, Christen WG, Stangos NT (2005) Primary pars plana vitrectomy versus scleral buckle surgery for the treatment of pseudophakic retinal detachment: randomized clinical trial. 25(8): 957-964. 